\title{
The impact of point-of-sale data in demand planning in the South African clothing retail industry
}

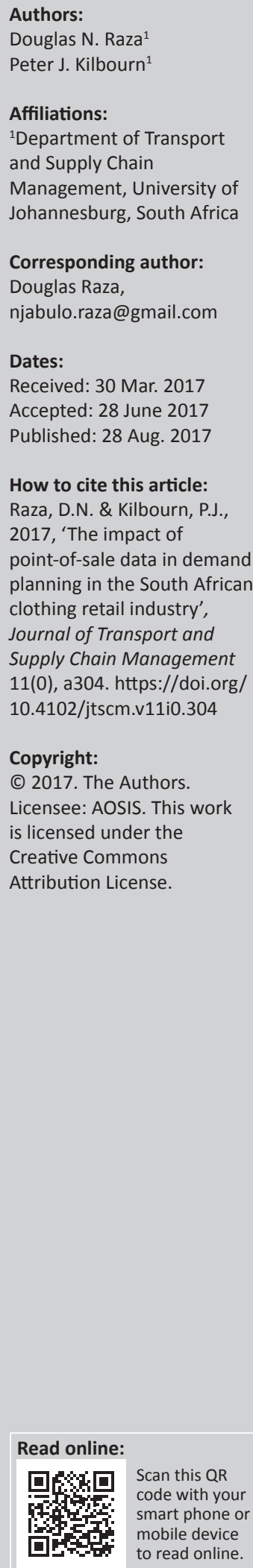

Background: In modern days' dynamic consumer markets, supply chains need to be value driven and consumer oriented. Demand planning allows supply chain members to focus on the consumer and create optimal value. In demand planning, Point-of-Sale (POS) data are an essential input to the process thereof; however, literature suggests that POS-based demand planning is often overlooked by demand planners in practice.

Objective: The main purpose of this study was to determine the extent to which South African clothing retailers use POS data in demand planning.

Method: This study followed the grounded theory approach based on the collection of qualitative data. The data collected was analysed following the grounded theory analysis using codes that resulted in various categories which then developed into themes.

Findings: Findings suggest that companies within the clothing retail industry make considerable use of POS data and is a fundamental input factor in the demand planning process. However, this study also found that POS data cannot be applied in the planning for all types of clothing products, and that there are variables other than POS data that form a critical part of the demand planning process.

Conclusion: POS data plays a fundamental role is the demand planning process and should be accurately collected and used with other qualitative and quantitative factors as an input factor to the demand planning process. The role of POS data in demand planning is expected to grow as customers are becoming increasingly demanding concerning customer service levels.

\section{Introduction}

\section{The need for understanding customer demand}

Responding to volatility in market conditions, and the resulting customer demand patterns, has proved to be the biggest challenge for supply chain executives and, not surprisingly, became a key investment area (Butner 2010). Supply chains often fail because of a lack of understanding of the makeup and nature of consumer demand. This failure to understand demand leads to a mismatched supply chain design (Blecker, Kersten \& Meyer 2009). Having a demand-driven approach could assist members of the supply chain to develop a customer-focused mind-set (Hitachi Consulting 2009; Lawless 2014). In the context of volatile market conditions, Bursa (2008:28) states that 'the demand driven supply chain is a powerful weapon for businesses of all sizes'.

\section{Demand planning and its role in customer value creation}

'Demand planning is a supply chain activity that uses sales forecast as one of multiple inputs to create a demand plan aligned with financial goals and inventory plans' (PWC 2012:2). Demand planning requires information input and insight contributions from different functions of the business. The demand planning process is not performed on a silo basis or in isolation but involves a considerable amount of collaboration with other departments including supply chain, sales, finance, marketing, operations and consumer insights (Gallucci 2015). Furthermore, to enhance the objectivity of demand planning, the practice requires an integration of numerous unbiased experts for obtaining required forecasts (Vlckova \& Patak 2010:1121).

Demand planning allows businesses to understand the nature of consumer demand and ensures that the supply response is suited to this demand. Failure to understand the nature of demand for the business's products results in a mismatch between demand and supply; this could be an oversupply or a product shortage (Lawless 2014). Firstly, poor demand visibility can result in 
inaccurate demand and understated demand forecasts causing inventory stock-outs. A stock-out results when the ordered product or demand is greater than the available product or supply. Pienaar and Vogt (2012) suggest that product stock-outs result in back order costs, cost of a lost customer and cost of a lost sale.

The second phenomenon is when a lack of visibility of consumer demand and overstated demand forecasts result in overstocking at different points of the supply chain. Uncertainty caused by poor supply chain visibility, especially of retail level point-of-sale (POS) information, also leads to the need for high levels of safety stock. This continued amplification of orders to prevent against stock-outs results in high order and demand variability. The increase in demand variability moving upstream of the supply chain results in a phenomenon termed the bullwhip effect. Figure 1 illustrates this phenomenon.

According to Lee, Padmanabhan and Whang (2004:1887), 'the bullwhip effect is the amplification of demand variability from a downstream site to an upstream site'. The bullwhip effect leads to tremendous supply chain inefficiencies that include undue inventory investment, misguided capacity plans, poor transport plans and missed production schedules (Lee et al. 2004). Pienaar and Vogt (2012) suggest that the excess inventory within the supply chain results in capital costs, handling and storage cost and cost of risk. In recognition of these costs and drawbacks associated with poor demand forecasts, it is therefore necessary to seek ways to improve the effectiveness of the demand planning task. 'The value of collaborative demand and supply planning between partners can be understood through improved operational, financial benefits, process and relationship benefits' (Shepard 2012:6).

\section{The role of point-of-sale data in demand planning}

Point-of-sale data can substantially improve the degree of a supply chain's visibility. Schrieber (2005) contends that the more visible the demand, the better the chance of accurate demand forecasts. POS data are comprised of the information that is collected at the point where a product is bought by the final consumer and allows the measurement of demand in the last part of the supply chain, more specifically, the amount of product that the consumer buys (Simon 2008). POS data are available to supply chain members either directly from the retailers themselves or in syndicated data from syndicated data vendors like AC Nielsen and Information Resource Inc. who are third parties in these information transactions (Simon 2008).

Demand planners use different data sets to determine forecasts: these could be previous shipments from the manufacturer's warehouse or distribution centre to the retailer; orders placed by customers (retailers); or POS data. Of all these forms of data, POS data are the closest

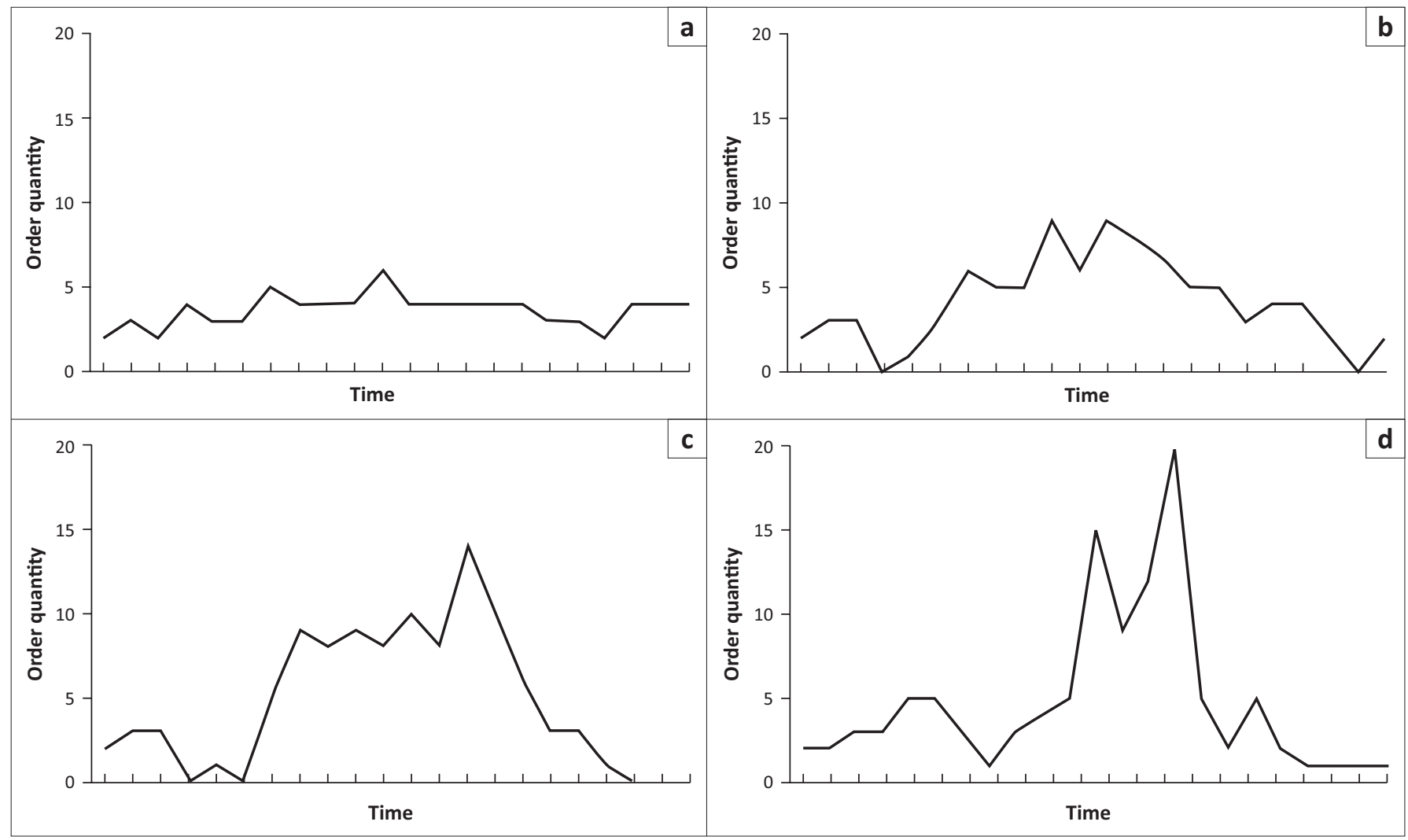

Source: Lee, H.L., Padmanabhan, V. \& Whang, S., 2004, 'Information distortion in a supply chain: The bullwhip effect', Management Science, 50(12 supplement), 1875-1888. https://doi.org/10.1287/ mnsc.1040.0266

FIGURE 1: Bullwhip effect - Increased variability of orders up the supply chain. (a) Consumer sales, (b) retailer's order to manufacturer, (c) wholesaler's orders to manufacturer and (d) manufacturer's order to supplier. 
representative of the true consumer consumption of a product as these suffer minimal distortion caused by consumer-level promotions and discounts (Lapide 2005). POS data have the following attributes that deem them the most valuable form of data in demand planning:

- Improve forecast accuracy (Bursa 2008).

- Enhance the implementation of collaborative strategies (Andres 2008:38).

- These are the best reflection of demand (Keifer 2010).

- These are free from inventory decisions (Bursa 2008).

\section{Clothing retail industry and point-of-sale-based demand planning}

This study is focused on the South African clothing retail industry. The South African formal clothing retail industry is principally made up of a few large retailing organisations as evidenced by the fact that in 2006 the top five retailers accounted for over $70 \%$ of South Africa's clothing sales (Gauteng Treasury Quarterly Bulletin 2012). In the official formal classifications of the Standard Industrial Classification from Statistics South Africa (StatsSA), the clothing retail sector is termed clothing, footwear and textiles (CFT).

A report by StatsSA (2015) on 2014 retail trade sales shows that CFT retail had the second highest sales revenue after general dealers. Figure 2 depicts that CFT retail is second behind general dealers, having $21 \%$ of the total retail revenue.

The South African clothing retail sector has experienced a healthy growth in recent years, thus attracting new entrants. Figure 3 shows the increase in sales revenue within the South African clothing retail industry over the past few years.

In the clothing industry, demand for clothing items is easily affected by several variables that include seasonal weather changes, actions of opinion leaders and other changes such as variations within the state of the economy (Moisanen

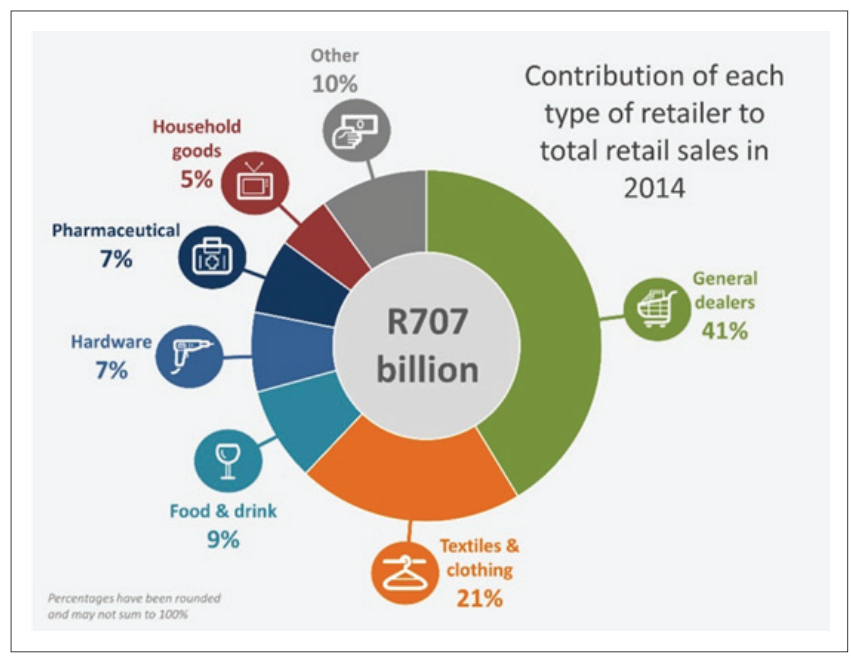

Source: Statistics South Africa (StatsSA), 2015, Retail sector growth losing steam, Quarter 2015, Pretoria

FIGURE 2: Retail trade sales for 2014.
2014). Based on the nature of the clothing industry, there is a need for clothing manufacturers and retailers to achieve a balance between their demand and supply processes. Effective demand planning assists in the achievement of this balance (Williams \& Waller 2011). The usage of POS data in demand planning and forecasting greatly improves the accuracy of these forecasts. In a volatile clothing industry with complex consumers, POS data become an indispensable tool (Williams \& Waller 2011).

\section{Problem statement}

This study focuses on how retailers in the South African clothing retail industry use POS data to achieve effective demand planning. The clothing industry is one of the industries that is demand focused, and it is highly consumer driven. Retailers in this industry have closer interaction and interface with the consumer and thus have greater influence in this consumer-driven supply chain as they are in possession of valuable consumer information (Gereffi \& Frederick 2010; Lu, Karpova \& Fiore 2011).

Moisanen (2014) and Thomassey (2014) specifically write on the importance of POS data-based demand planning in the clothing retail industry. Thomassey (2014:9) holds that the clothing industry is 'a fascinating sector for the sales forecasters; the long time-to-market characteristic of the clothing industry contrasts with the short life cycle of products, thus complicating the forecasting process'. Despite difficulties associated with predicting sales, accurate sales forecasting in the clothing industry is considered important 'due to the long lead times caused by the relatively recent trend of sourcing production out to other countries' (Moisanen 2014:1).

After a thorough analysis of various online data sources, no study was found that specifically addresses the usage of POS data in demand planning processes in South Africa's clothing retail sector. Therefore, amid the ever-increasing importance and need for accuracy in demand planning and the complexity of consumer markets, there is a need for information about the use of POS data by South African clothing retail firms.

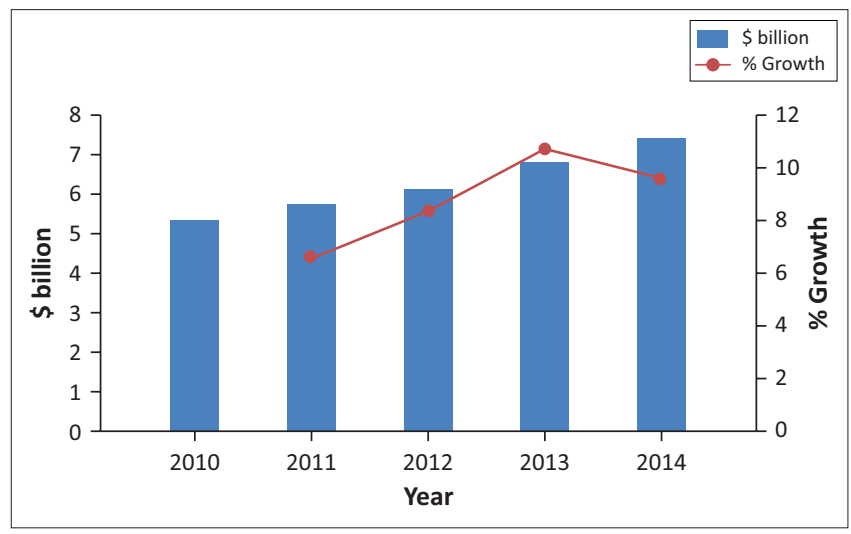

Source: Euromonitor, 2015, Retailing in South Africa, Euromonitor, viewed 03 August 2015 from http://www.euromonitor.com/retailing-in-south-africa/report

FIGURE 3: South African apparel retail industry value: \$ billion, 2010-2014. 


\section{Research objective}

Based on the above-mentioned problem statement, two types of study objectives resulted.

\section{Primary objective}

The primary objective of this study was to determine the extent to which firms in the South African clothing industry use POS data in demand planning and how the use of POS data can be increased.

\section{Secondary objectives}

The secondary objectives of this study were to:

- discover how demand planning is performed in the South African clothing retail industry

- determine the systems employed in the collection and dissemination of POS data in the South African clothing industry

- determine the role of POS data in demand planning within the South African clothing industry

- determine the challenges and problems faced by South African clothing retailers in the collection, dissemination and usage of POS data in demand planning

- determine the possible future of POS data in the process of demand planning.

\section{Research strategy Research approach}

In order to address the already stated research questions, a qualitative research approach was used in this study. The qualitative approach was deemed the most suitable approach for this study as the objective is to gain great detail and indepth understanding of the usage of POS data in demand planning. Firstly, as part of the research methodology, secondary research was conducted through a literature study. Through this literature study, the research gap was identified and the critical constructs for the study were defined. In the primary research, the grounded theory research strategy or design is followed, which according to Saldaña (2011) is a strategy whereby the researcher continually compares collected data units through a series of cumulative coding cycles in order to determine emerging themes and categories.

\section{Participants}

In the context of this study, the population consists of the major clothing retail companies in South Africa. The sample frame used in this study was based on a combination of lists of companies represented by the National Clothing Retail Federation of South Africa and Silo, a leading digital brand content provider and source of unified retail intelligence, retail analytics and product analytics in South Africa. From this sampling frame, a sample of eight retail stores was selected using heterogeneous purposive sampling which is a type of non-probability sampling. In purposive sampling, sampling units are chosen to fit particular purpose (Leedy \&
Ormrod 2014:221), based on the objectives of the study, the sample was selected based on the number of outlets the retailer had.

\section{Methods of data gathering}

In this sample of eight clothing retail stores, individuals working as demand planners of these companies were contacted and were all interviewed through a questionnaire of semi-structured questions. The interviewees were comprised of individuals at between middle and top management levels whose work involves demand planning for the respective companies. The interviews were all digitally recorded and were transcribed using the actual words into Microsoft Word documents. Table 1 shows the duration and locations for the respective interviews.

\section{Data analysis}

The inductive rationale was followed in the analysis of the collected data, which applies when data are collected and explored in order to observe the themes or issues that emanate from the data, and to discover which issues to follow up and concentrate on (Saunders, Lewis \& Thornhill 2011). As this study followed the grounded theory research strategy, the grounded theory analysis was used. As described by Saldaña (2011), grounded theory analysis is an analytical process whereby the researcher continually compares small data units through a series of cumulative coding cycles in order to determine a range of dimensions to the emerging themes and categories. The transcribed interviews were coded using a computer-assisted qualitative data analysis software called Atlas.ti. This coding process involved the careful reading of the transcribed data, line by line, and dividing it into meaningful analytical units (Maree 2007:105).

Trustworthiness was built into the collection of the data through purposive sampling, which requires a careful consideration of the characteristics of individual participants (Leedy \& Ormrod 2014:221). Additionally, trustworthiness was also built by giving the assurance of anonymity to the research participants and through the usage of a consistent method of collection to avoid any form of bias (Saunders et al. 2011:331). Trustworthiness of the analysis was ensured through the process of crystallisation which Maree (2007:81) refers to as credible in so far as those reading the data and analysis will be able to see the same emerging patterns.

TABLE 1: Duration and location of interviews.

\begin{tabular}{lcl}
\hline Company & Duration $(\mathbf{m i n})$. & Location \\
\hline A & 43 & Johannesburg \\
B & 25 & Johannesburg \\
C & 24 & Cape Town \\
D & 28 & Cape Town \\
E & 26 & Cape Town \\
F & 31 & Cape Town \\
G & 23 & Cape Town \\
H & 34 & Johannesburg \\
\hline
\end{tabular}




\section{Discussion}

Through the analysis process, various categories and themes emanated. Table 2 depicts a framework showing the key findings and how they are linked to the objectives.

These themes and issues summarised in Table 2 are described in the following section, ordered in the manner in which they address the secondary research questions.

\section{The demand planning process in the South African clothing retail industry}

The analysis of the collected data reveals that companies in the South African clothing retail sector follow different steps in demand planning, and thus there is no universal framework followed in the process of demand planning. Despite the differences in the approaches followed by the different companies, similarities were noted. These similarities include the following:

- Demand planning is considered a fundamental business process - of the many reasons supporting the importance of demand planning within these clothing retail companies, its influence on inventory positioning and availability stood out.

- The demand planning process is an iterative process - the process has a given series of steps where different input factors are considered, revised and reviewed continually to determine the expected demand.

- Demand planning in the clothing industry is largely based on historical data - the data could be from past sales periods or POS data.

- The demand planning process is a collaborative process demand planning role is not a 'one-man show', although much of the responsibility lies with these demand planners not solely their responsibility, other organisational functions and supply chain partners are also involved, for example, the marketing and buying functions.

\section{The nature of the South African clothing retail industry}

Based on the information gathered, the South African clothing industry has a supply chain that is characterised by

TABLE 2: Key findings and their relationship with the research objectives.

\begin{tabular}{ll}
\hline Objective & Key finding \\
\hline $\begin{array}{l}\text { 1. To discover how demand planning is } \\
\text { performed in the South African } \\
\text { clothing retail industry }\end{array}$ & $\begin{array}{l}\text { There is no universal framework followed } \\
\text { in the process of demand planning; } \\
\text { however, there are some notable } \\
\text { similarities in the processes. }\end{array}$ \\
$\begin{array}{ll}\text { 2. To determine the systems employed } \\
\text { in the collection and dissemination } \\
\text { of POS data in the South African } \\
\text { clothing industry }\end{array}$ & $\begin{array}{l}\text { Technology plays a vital role in the capture } \\
\text { of data. Data collected at the point of } \\
\text { purchase contain various details about a } \\
\text { specific sale and are used by the different } \\
\text { organisational functions. }\end{array}$ \\
$\begin{array}{ll}\text { 3. To determine the role of POS data in } \\
\text { demand planning within the South }\end{array}$ & $\begin{array}{l}\text { POS data play a fundamental role in } \\
\text { demand forecasts and are considered a } \\
\text { majorican clothing industry }\end{array}$ \\
$\begin{array}{ll}\text { 4. To determine the challenges and } \\
\text { problems faced by South African } \\
\text { clothing retailers in the collection, } \\
\text { dissemination and usage of POS } \\
\text { data in demand planning }\end{array}$ & $\begin{array}{l}\text { Two common problems or challenges } \\
\text { identified were technology-related } \\
\text { problems and human error. }\end{array}$ \\
\hline $\begin{array}{l}\text { 5o determine the possible future of } \\
\text { POS data in the process of demand } \\
\text { planning }\end{array}$ & $\begin{array}{l}\text { The usage of POS data is expected to } \\
\text { increase; however, there are challenges } \\
\text { that need to be overcome in order to get } \\
\text { the optimal benefit of using POS data in } \\
\text { demand planning. }\end{array}$ \\
\hline
\end{tabular}

POS, point-of-sale. much dependence on imported products. Notably, the participants mentioned China as the biggest contributor to the products that they sell. A critical issue in demand planning is the demand volatility of concerned products. From a South African clothing retail perspective, some products are more stable and those are easier to forecast for. On the other hand, some products are more volatile and are characterised by a high level of uncertainty.

The analysis of the collected data revealed a dichotomy in terms of types of products that are sold within the South African clothing retail industry. The participants directly and indirectly made a distinction between two broad product categories. The first category comprises products with a more stable demand and makes provision for products that are termed by the different participants as yearly products or replenishment items, or core products. Customers demand these products throughout the year, thus the retailer should have them in stock all year around. Examples under this category include white or black t-shirts, socks and basic underwear.

The second category comprises more volatile products with a greater level of uncertainty; the products could be new to the market and therefore there is no historical reference point to guide forecasts. Moreover, these kinds of products could be what is termed seasonal products or trend items or non-core. This category of products changes over time and therefore is more volatile. These products are said to be more difficult to plan for; a vivid response on this phenomenon by a participant is given below:

For the seasonal goods, we have minimal forecasting because that process is generally led by fashion trends which are qualitative rather than quantitative. (Participant 4, Male, Senior Demand planner)

\section{Point-of-sale data collection and dissemination}

All the research participants cited the usage of POS data collection systems in the companies that they work for. The systems collect the information of a particular sale at store level; the data scanning or collection systems are linked to a central system where all the sales information from different stores is aggregated and stored. The different users can retrieve the stored information as and when needed. Data collected at the point of purchase contain various details about a specific sale; this information is used for various purposes by the different organisational functions. The availability of POS data to the different supply chain members has an impact on supply chain visibility. The quicker the sharing of this POS data to the supply chain members, the better the visibility.

In the collection, dissemination and usage of POS data, it is notable that technology plays a fundamental role. Findings suggest that modern-day demand planning depends on the availability of suitable technology. Clothing retail companies have thousands of stock-keeping units, and it would be a difficult task to capture, store and retrieve this information if 
the current technological systems were not in place. Findings show that the role of technology in the demand planning process includes the following:

- Data capturing - This is conducted when stock is received in stores and also when a sale takes place, normally performed through barcoding and the complementary scanning system.

- Data dissemination - Technological systems have greatly improved the speed of data transfer, for example, some demand planners are able to view the sales as they happen on a live system.

- Data storage - The captured data are stored in a company database and can be retrieved as and when needed.

- Forecasting-Numerous algorithms are used in determining forecasts, and performing this task without the help of software would be strenuous and time consuming.

- Internal and external communications - Throughout the iterative process of demand planning, the representatives of the different company departments need to stay in close communication and various technologies facilitate these actions.

\section{The role of point-of-sale data in demand planning}

The collected POS data are used for different purposes by different organisational functions; more relevant to this study was the usage of POS data in demand planning. Findings show that POS data play a fundamental role in demand forecasts and are considered a major input factor. Forecasting and demand planning are mostly about determining the future demand in order to ensure optimal inventory levels at various points of the supply chain. POS data are most suitable for this because of the advantages that have already been mentioned in this study. However, there are some situations where POS data are not relevant and these include the following:

- trend items which are influenced by fashion trends and have no direct link to previous sales data

- new product lines that have not been previously sold by the company, so there is no previous history

- supplier-dictated products. Some suppliers of major brands dictate the range of products as well as the quantities that retailers should stock.

Over and above the usage of POS data, demand planning also considers other input factors. The involvement of other company departments means various issues are brought to the table. These factors include:

- sales objectives and company strategy

- competition and competitor activities

- promotions and other marketing activities

- the economy - inflation and consumer buying power

- lead times

- supplier constraints

- social factors such as lifestyle changes.

\section{Challenges and problems in point-of-sale-based demand planning}

Findings also revealed that there are problems faced in the use of POS data in demand planning. Two common problems identified were technology-related problems and human error. Firstly, the users of POS data sometimes face technical problems associated with the operation of the systems and technology. One participant mentioned the following on technological problems:

We face different problems including transmission, downtime, power outages and disconnection problems. (Participant 4, Male, Senior demand planner)

Secondly, the problems associated with human error may include among other aspects, the double scanning of a product and the mismatching of products and barcode tags. Another problem linked to human interference is the manipulation of data by store-level managers. This right of being able to manipulate store data can make the system vulnerable to unethical tendencies and actions like fraud and pilferage. A further problem faced at a demand planning level is the subjectivity and bias in the interpretation of the collected information. Users of POS data must make sense of the collected data by extrapolating various meanings of the data. One participant mentioned the following in this regard:

Any data that you get is subjective and all dependent on interpretation. So if you are an inexperienced planner you can misread your data and present information that is incorrect. (Participant 2, Male, Demand planner)

\section{The future of point-of-sale data in demand planning in the South African clothing retail industry}

The usage of POS data in demand planning is expected to grow within the South African clothing retail industry; this can be attributed to the above-mentioned advantages that POS data possesses. Although the usage of POS data is expected to increase, there are challenges that need to be overcome in order to obtain the optimal benefit of using POS data in demand planning. One area of improvement, common to some participants, is training and education. There is a need for training of the different personnel that deal with POS data at any point, be it collection, analysis or usage. There is also a need to train managers on the importance of POS-based demand planning.

Another area with potential for improvement concerned the time lag between collection and availability of POS data on the central planning system. Shorter time lags will allow quicker response to the stock requirements in the respective stores, and will allow the demand planners to quickly sense any shifts in consumer tastes and preferences as well as demand patterns for their products. Shorter time lags take advantage of the real value of POS data, which is the fact that POS data are as close to 'actual demand' figures that most companies can obtain. Therefore, late access to these data defeats the purpose thereof. The quicker transfer of POS data to the various members of the supply chain also enhances supply chain visibility and integration.

The other area of possible improvement lies with the system and technology used to collect and analyse POS data. Firstly, 
it is suggested that the system should block human manipulation of data on the system. This will ensure that the integrity of the data is preserved. Furthermore, better systems are being developed and the old systems are being upgraded.

\section{Conclusion}

This study investigated the usage of POS data in demand planning in the South African clothing retail industry. The objective was to determine the extent to which South African clothing retail companies use POS data and to discover the processes followed and systems used in this regard.

From the literature study it could be concluded that demand planning is an important part in the management of supply chains based on the influence and impact of its output on the various supply chain members. Demand planning affects inventory positioning, replenishment decisions, ordering and production decisions. Considering all these factors, companies need to ensure that the process of demand planning is carried out effectively and that different functions collaborate in this process to factor in all the issues that influence demand.

The main objective of this study was to determine the extent to which POS data were used in demand planning processes of South African clothing retailers and how the use of these data could be increased. Findings from this research showed that South African clothing retailers extensively collect POS data and use them for various purposes including having them as an input to the demand planning process. POS data were proved to play a fundamental role in the process of demand planning as they are considered the foundational input in this process. Furthermore, its importance is substantiated by the inherent characteristics it has that enhance forecasting accuracy and planning effectiveness. However, POS data are not used in isolation; there are other qualitative and quantitative factors that need to be considered as inputs in the demand planning process.

The role of POS data in demand planning is expected to grow as customers are becoming increasingly demanding concerning customer service levels. Companies should therefore invest and implement robust POS collection and dissemination systems and technologies to ensure that they can leverage the advantages of POS data. The timely capturing and dissemination of POS data are of high importance. A company's ability to match product supply to customer demand leads to high levels of efficiency and effectiveness; POS data can play a fundamental role in enhancing this ability.

Notable limitations of the study include the fact that purposive sampling was used and the sample may not be the best representation of the population; thus findings cannot be generalised. Furthermore, the identification of businesses that form part of the sampling frame was from memos from associations under which these businesses are registered; this could be a limitation because of the fact that not all the clothing companies are registered under these associations.
This research has identified the following prospective future research opportunities:

- optimising the collection of POS data - in the context of timing and accuracy of POS data collection being important in the demand planning process

- the usage of qualitative variables in demand planning

- the potential for local sourcing in the South African clothing industry.

\section{Acknowledgements Competing interests}

The authors declare that they have no financial or personal relationships that may have inappropriately influenced them in writing this article.

\section{Authors' contributions}

D.N.R. performed the literature study and the primary research and wrote the article from the findings of his M.Com Logistics Management dissertation at the University of Johannesburg. P.J.K. acted as the supervisor of the dissertation and academically reviewed the work throughout the research process and provided direction to the study.

\section{References}

Andres, F., 2008, 'Demand planning and forecasting with POS data: A case study', Journal of Business Forecasting Methods and Systems 27(4), 29.

Blecker, T., Kersten, W. \& Meyer, M., 2009, High performance logistics: Methods and technologies, Erich Schmidt Verlag GmbH \& Co. KG.

Bursa, K., 2008, 'How to effectively manage demand with demand sensing and shaping using point of sales data', The Journal of Business Forecasting 27(4), 26, viewed 04 August 2015, from http://connection.ebscohost.com/c/ articles/37299793/how-effectively-manage-demand-demand-sensing-shapingusing-point-sales-data

Butner, K., 2010, 'The smarter supply chain of the future', Strategy and Leadership 38(1), 22-31. https://doi.org/10.1108/10878571011009859

Euromonitor, 2015, Retailing in South Africa, Euromonitor, viewed 03 August 2015, from http://www.euromonitor.com/retailing-in-south-africa/report

Gauteng Treasury Quarterly Bulletin, 2012, The retail industry on the rise in South Africa, viewed 16 September 2015, from http://www.treasury.gpg.gov.za/ Documents/QB1\%20The\%20Retail\%2OIndustry\%20on\%20the\%20Rise.pdf

Gallucci, J., 2015, ' 7 behaviors of great demand planners', The Journal of Business Forecasting 34(1), 4, viewed 12 April 2015, from https://www.questia.com/ library/journal/1P3-3679188531/7-behaviors-of-great-demand-planners

Gereffi, G. \& Frederick, S., 2010, 'The global apparel value chain, trade and the crisis: Challenges and opportunities for developing countries', World Bank Policy Research Working Paper Series, viewed 05 August 2015, from http://www19.iadb. org/intal/intalcdi/PE/2010/05413.pdf

Hitachi Consulting, 2009, Six key trends changing the supply chain management today, Hitachi Consulting, viewed 13 March 2015, from http://www.sdcexec. $\mathrm{com} /$ news/10358095/six-key-trends-changing-the-supply-chain-managementtoday

Keifer, S., 2010, 'Beyond point of sale: Leveraging demand signals for forecasting', The Journal of Business Forecasting 29(2), 14

Lapide, L., 2005, 'Account level forecasting needs downstream data', The Journal of Business Forecasting 24(2), 17

Lawless, M., 2014, 'Predictive analytics: An opportunity for better demand planning and forecasting', The Journal of Business Forecasting 33(4), 44, viewed 12 April 2015, from https://www.questia.com/library/journal/1P3-3601906371/ predictive-analytics-an-opportunity-for-better-demand

Lee, H.L., Padmanabhan, V. \& Whang, S., 2004, 'Information distortion in a supply chain: The bullwhip effect', Management Science, 50(12 supplement), 18751886. https://doi.org/10.1287/mnsc.1040.0266

Leedy, P.D. \& Ormrod, J.E., 2014, Practical research, planning and design, 10th edn., Pearson, London.

Lu, Y., Karpova, EE. \& Fiore, A.M., 2011, 'Factors influencing international fashion retailers' entry mode choice', Journal of Fashion Marketing and Management: An International Journal 15(1), 58-75. https://doi.org/10.1108/1361202 1111112340 
Maree, K. (ed.), 2007, First steps in research, Van Schaik Publishers, Pretoria.

Moisanen, J., 2014, 'Demand forecasting in the apparel industry', viewed 16 September 2015, from http://urn.fi/URN:NBN:fi:amk-2014052910961

Pienaar, W.J. \& Vogt, J.J., 2012, Business logistics management: A value chain perspective, Oxford University Press, London.

PWC, 2012, Five steps to better demand plan clarity and accuracy, PWC Consulting Services, viewed 05 August 2015, from https://www.pwc.com/us/en/operationsmanagement/assets/demand-planning.pdf

Saunders, M.N., Lewis, P. \& Thornhill, A., 2011, Research methods for business students, Pearson Education, India.

Saldaña, J., 2011, Fundamentals of qualitative research, Oxford University Press, New York.

Schrieber, J., 2005, 'Demand visibility improves demand forecasts', The Journal of Business Forecasting 24(3), 32, viewed 12 April 2015, from http://search.proquest. com/openview/2cb89118bc1caab58a05f5e17dcf089c/1?pq-origsite=gscholar
Shepard, D., 2012, 'Collaborative demand and supply planning between partners', viewed 05 August 2015, from http://supplychainacuity.com/uploads/SCA Collaboration_Monograph_February2012.pdf

Simon, R., 2008, 'The ABCs of point of sales (POS) data', The Journal of Business Forecasting 27(4), 4

Statistics South Africa (StatsSA), 2015, Retail sector growth losing steam, Quarter 1 2015, Pretoria.

Thomassey, S., 2014, 'Sales forecasting in apparel and fashion industry: A review', in Intelligent fashion forecasting systems: Models and applications, pp. 9-27, Springer, Berlin, Heidelberg.

VIckova, V. \& Patak, M., 2010, in The 6th International Scientific Conference 'Business and Management 2010', Selected paper.

Williams, B.D. \& Waller, M.A., 2011, 'Top-down versus bottom-up demand forecasts: The value of shared point-of-sale data in the retail supply chain', Journal of Business Logistics 32(1), 17-26. https://doi.org/10.1111/j.2158-1592.2011. 01002.x 